Juliana Figueiredo Arreal ${ }^{1}$

Laura Cecilia López ${ }^{2}$

\section{Trabalhadoras de turno noturno: relações de gênero, produção de vulnerabilidades e promoção da saúde}

\author{
Night shift workers: gender relationships, production of \\ vulnerabilities and health promotion
}

\begin{abstract}
1 Prefeitura Municipal de Eldorado do Sul, Secretaria Municipal de Saúde. Eldorado do Sul, RS, Brasil.

${ }^{2}$ Universidade do Vale do Rio dos Sinos, Programa de Pós-Graduação em Saúde Coletiva. São Leopoldo, RS, Brasil.
\end{abstract}

Contato:

Laura Cecilia López

E-mail:

lauracl@unisinos.br

Trabalho baseado em dissertação de mestrado de Juliana Figueiredo Arreal intitulada "Saúde da Mulher Trabalhadora de Turno Noturno", defendida em 2012, na Universidade do Vale do Rio dos Sinos.

O trabalho foi apresentado no $X$ Congresso da Abrasco, em Porto Alegre, em 2012, e publicado nos anais como resumo.

As autoras declaram não haver conflitos de interesse e que o trabalho não foi subvencionado.

Recebido: 27/05/2013

Revisado: 22/06/2014

Aprovado: 23/06/2014

\section{Resumo}

Objetivo: analisar os impactos que o trabalho noturno exerce sobre a saúde de trabalhadoras do setor metal-mecânico. Métodos: a partir do olhar sobre as relações de gênero, foca-se como a organização e a divisão social do trabalho afetam a vida cotidiana dessas mulheres. Examinam-se essas experiências à luz das reflexões sobre vulnerabilidades, produzidas na relação gênero/trabalho/ saúde. Trata-se de um estudo qualitativo, realizado em 2012, empregando-se entrevistas semiestruturadas com nove trabalhadoras de turno noturno de uma empresa localizada na região metropolitana de Porto Alegre/RS. A análise dos dados foi guiada pelo método de Análise de Discurso. Foram construídos eixos analíticos com base no diálogo entre a literatura e os discursos das entrevistadas. Discussão: identificaram-se desigualdades de gênero que impactam nas condições de saúde das trabalhadoras metalúrgicas de turno noturno, apontando-se algumas especificidades das vivências dessas trabalhadoras no local pesquisado: agudo processo de subvalorização do trabalho, descanso limitado, alimentação irregular, dificuldades na organização da vida fora do ambiente de trabalho, falta de acesso a suportes sociais que apoiem as atividades femininas, sobrecarga das responsabilidades assumidas, que, muitas vezes, causam sofrimento mental e/ ou outros adoecimentos.

Palavras-chave: gênero; saúde; trabalho; trabalho em turnos; turno noturno.

\begin{abstract}
Objective: to analyze the impacts of night shift work on the health of metalmechanical women workers. Methods: from the perspective of gender relations, this study focuses on how the organization and social division of labor affect the everyday lives of these women. It examines experiences in light of these reflections on vulnerabilities, produced in the gender/work/health relationship. It is a qualitative study, held in 2012, using semi-structured interviews with nine night shift workers of a company located in the metropolitan region of Porto Alegre, Rio Grande do Sul state. Data analysis was based in the method of discourse analysis. Analytical lines were built on the dialogue between the literature and the interviewees' discourses. Discussion: we identified gender inequalities that may impact on night shift metal-mechanic workers' health, pointing at some particularities of these workers' daily lives in the researched sector, such as: acute process of work underestimation, limited rest hours, irregular eating, difficulties to organize their lives off work, lack of access to the social structures that can back their female activities, and over charge of assumed responsabilities that can cause mental suffering and/or other illnesses.
\end{abstract}

Keywords: gender; health; work; shift work; night work. 


\section{Introdução}

Este artigo analisa os impactos que o trabalho noturno exerce sobre a saúde de trabalhadoras do setor metal-mecânico. A partir de um olhar que leva em consideração as relações de gênero, verifica-se como a organização e a divisão social do trabalho afetam a vida das mulheres objeto deste estudo. Pretende-se examinar a experiência cotidiana feminina à luz das reflexões sobre vulnerabilidades em saúde, ao levar em consideração os efeitos das desigualdades de gênero nos processos de saúde-adoecimento. Conceituam-se as vulnerabilidades como contextos gerados a partir de condições sociais de violência cotidiana e de injustiça estrutural, que provocam uma fragilidade política e institucional na promoção, proteção ou garantia de direitos de determinados indivíduos ou grupos (AYRES et al., 2009).

Nesse sentido, focaremos a relação entre gênero, trabalho e saúde, para apontar algumas lacunas na promoção de saúde no universo pesquisado. Entendemos a promoção de saúde como ações voltadas para indivíduos e coletividades, através de políticas públicas intersetoriais que incluam amplamente os direitos de cidadania (BUSS, 2000) e que possibilitem a construção intersubjetiva (ALMEIDA FILHO; CASTIEL; AYRES, 2009) entre os atores envolvidos.

No Brasil, nas últimas décadas, assistimos o crescente incremento das mulheres no mercado de trabalho " [...] de forma intensa e diversificada, sem retrocesso, apesar das crises econômicas que abalaram o país" (ARAÚJO; OLIVEIRA, 2006, p. 185). As mulheres estão exercendo diferentes profissões, atingindo diversos setores, bem como estão estudando e se qualificando mais do que os homens (OLIVEIRA, 1997; BRUSCHINI, 2007). Porém, as transformações relativas ao aumento da escolaridade ainda não significam salários iguais aos dos homens, persistindo as desigualdades de gênero no mercado de trabalho (BRITO, 2011).

Presencia-se uma construção social de gênero, que provoca que homens e mulheres trabalhadores sejam, desde os núcleos familiares, diferentemente qualificados e capacitados para o ingresso no mercado de trabalho. Sendo assim, muitas vezes a situação desfavorável vivenciada pelas mulheres é reforçada, já que a carreira é marcada pela descontinuidade (maternidade, criação dos filhos) e por salários menores (BRITO, 2000; HIRATA; KERGOAT, 2007; OLIVEIRA, 1997, 1999).

Os processos de globalização e de expansão das políticas neoliberais e de reestruturação produtiva têm efeitos na precarização do trabalho, em concomitância com as mudanças nas condições laborais por enfraquecimento ou por perda de direitos sociais, direitos sindicais, de prevenção e de segurança no trabalho. Somado à organização das relações de gênero no mercado de trabalho, esses fenômenos geram condições de maior vulnerabilidade para as mulheres (GIANNASI, 1997; BRITO, 2000).

Ao analisar as condições de trabalho como mantenedoras das desigualdades de gênero, devemos considerar também a produção de desigualdades em vários contextos sociais, ligados às esferas produtivas e reprodutivas (OLIVEIRA, 1999; HIRATA; KERGOAT, 2007).

Ainda, para refletir sobre os processos de saúdeadoecimento das mulheres trabalhadoras, deve-se considerar que as mulheres têm papéis sociais diferenciados, assim como experiências distintas de viver, de sofrer e de adoecer, permeadas por relações de gênero. Para contemplar essa diversidade, precisase de um conceito integral de saúde, incluindo não só os aspectos referentes aos processos de adoecimento no ambiente de trabalho, como também os impactos dos fatores que dizem respeito à reprodução social (OLIVEIRA; BARRETO, 1997; MINAYO-GOMEZ; MACHADO; PENA, 2011).

A coexistência da produção e da reprodução em algumas circunstâncias pode promover a saúde, já que a oportunidade de ter seus próprios rendimentos e o apoio familiar podem compensar as dificuldades advindas dos processos de trabalho. Contudo, em outros casos, podem gerar conflitos e contradições que não conduzem à qualidade de vida e ao bemestar, gerando mais transtornos e adoecimentos para as mulheres (SCHIRMER, 1997; OLIVEIRA, 1999; BRITO, 2000, 2005).

Estudos apontam que as fronteiras entre o trabalho e o lar são mais permeáveis para as mulheres do que para os homens, estando sua saúde mental e física moldada nas suas vivências como trabalhadoras e mães. Por isso, os conflitos decorrentes das relações de gênero, nas quais cabe à mulher o equilíbrio individual entre os tempos doméstico e social, podem gerar maiores incidências de vivências depressivas nas mulheres (SCHIRMER, 1997; OLIVEIRA, 1999; HIRATA; KERGOAT, 2007).

Sendo assim, cabe a discussão sobre as vulnerabilidades experienciadas por trabalhadoras que exercem suas atividades empregatícias em um período de trabalho inverso ao da maioria da população - o turno noturno, em um setor que essencialmente emprega homens: o setor metal-mecânico. Esse setor constituiu-se historicamente como sendo um ambiente de trabalho masculino, no qual aptidões como força, capacidade física e conhecimentos técnicos sobre mecânica são culturalmente vinculados ao homem. No entanto, nos últimos anos, as trabalhadoras vêm adquirindo maior espaço nesse ambiente, mesmo que ainda menor que o dos homens (SARDENBERG, 2004). 
A maioria dos estudos realizados no Brasil que abarca uma dinâmica mais ampla relativa ao turno noturno está relacionada à investigação de uma série de autores e autoras (MORENO; LOUZADA, 2004; FISCHER; LIEBER, 2007; ROTENBERG, 1997, 2004). Além disso, os trabalhos atuais sobre gênero e trabalho noturno estão mais restritos às trabalhadoras da área hospitalar, principalmente as da enfermagem e as da medicina (GASPAR; MORENO; MENNABARRETO, 1998; OLIVEIRA, 2005; MANHÃES, 2009; MEDEIROS et al., 2009; SILVA; MARTINO, 2009). Cabe citar, também, as pesquisas de cunho epidemiológico com análises de risco, que focalizam os agravos à saúde gerados a partir do trabalho noturno (RÉGIS-FILHO, 2002; CRISTOFOLETTI, 2003; MOLINO et al., 2008; MACAGNAN, 2010).

Identificou-se, então, uma lacuna de conhecimento referente à saúde das trabalhadoras de turno noturno - assim como uma lacuna em relação à saúde das mulheres no setor metal-mecânico - como problemática abordada pela Saúde Coletiva, com abordagem qualitativa. O presente estudo visou contribuir com tal reflexão e dialogar com os estudos feministas que elencam a relação entre gênero, trabalho e saúde em uma perspectiva que aproxima o marxismo e o pósestruturalismo, a fim de entender como se dá a produção de desigualdades e de seus efeitos no cotidiano das mulheres (OLIVEIRA, 1997, 2008; ROTENBERG, 2004; SARDENBERG, 2004).

\section{Métodos}

O presente estudo parte de uma abordagem qualitativa, privilegiando a óptica dos atores envolvidos e suas experiências sociais (FLICK, 2009; MINAYO, 2010). A observação direta no ambiente de trabalho foi utilizada de maneira complementar, para melhor compreender e contextualizar as falas das entrevistadas. A principal técnica aplicada foi a entrevista semiestruturada, com questões referentes à organização da vida cotidiana das mulheres dentro e fora do trabalho. Redes sociais de apoio, cuidados com a saúde, percepções sobre a saúde, organização da jornada de trabalho e vivências no espaço de trabalho compuseram o teor do roteiro semiestruturado. Em síntese, dois eixos percorreram as questões: indagações sobre a percepção de diferenças/ desigualdades entre homens e mulheres; e relação trabalho noturno/saúde na vida das mulheres.

As entrevistas foram gravadas e transcritas para melhor apreensão dos discursos. Com relação às transcrições, foram realizadas com respeito aos traços característicos de fala e às entoações expressivas de cada locutor. Em vista disso, optou-se por mantê-las o mais próximo possível da realidade de fala do entrevistado (ou seja, sem correção ortográfico-gramatical). Quanto às pontuações, foram organizadas com base na apreciação (ênfase) que o locutor dava às palavras em seu discurso.

O universo empírico foi constituído por mulheres trabalhadoras de turno noturno (no horário das $22 \mathrm{~h}$ às $5 \mathrm{~h}$ ) que atuam no setor metal-mecânico, todas com vínculo com o sindicato da categoria - instituição procurada antes do contato com as mulheres alvo deste estudo, e que promoveu, através de uma interlocutora, as primeiras relações com as trabalhadoras. Algumas entrevistas ocorreram dentro do sindicato, e as restantes no interior de uma empresa de grande porte, conforme agendamento prévio. Ambas as instituições estão situadas na parte norte da região metropolitana de Porto Alegre/RS, denominada também como Vale do Rio dos Sinos. Essa região apresenta estrutura econômica com forte presença industrial de diversos setores, sendo considerada especializada na cadeia coureiro-calçadista.

O trabalho de campo ocorreu entre abril e agosto de 2012. Foram entrevistadas nove trabalhadoras, com idade entre 21 e 45 anos, sendo oito delas casadas, das quais sete tinham filhos com idade entre 6 e 24 anos. Dentre essas, uma delas estava no início da segunda gestação, no período da pesquisa. Todas elas moravam com o cônjuge e filho, exceto uma, que ainda não tinha filhos, e outra, que não era casada e morava com a mãe. Das nove trabalhadoras, no momento da pesquisa, apenas uma já havia saído do turno noturno.

A análise dos dados foi orientada pela perspectiva de Análise do Discurso (IÑIGUEZ, 2005), sendo os discursos fundamentais na (re)construção e reprodução das estruturas e da organização social. O corpus de análise foi construído a partir da transcrição das entrevistas e dos diários de campo, decorrentes das observações na empresa e no sindicato. Realizou-se a categorização dos enunciados, conforme eixos temáticos que emergiram dos discursos na triangulação entre as falas, nos diários de campo e nos achados bibliográficos (GIBBS, 2009; MINAYO, 2010).

Foram construídos dois eixos analíticos: o primeiro, ancorado no conceito de gênero, analisa as maneiras como as entrevistadas lidam com as desigualdades de gênero e com a divisão do trabalho também pautada por essas desigualdades, nas esferas da produção e de reprodução sociais. O segundo examina a produção de vulnerabilidades e os processos de saúde-adoecimento experienciados por essas trabalhadoras.

A pesquisa contou com a aprovação do Comitê de Ética em Pesquisa da Universidade, através do Protocolo 11/175 - 2011. Todas as entrevistadas assinaram um Termo de Consentimento Livre e Esclarecido. São utilizados nomes fictícios para identificar as entrevistadas, com o objetivo de manter o sigilo de suas identidades. 


\section{Resultados}

\section{“Dormia menos, mas estava lá...”: dinâmicas na vida das trabalhadoras}

Usamos o termo "gênero" como categoria analítica que se torna explicativa dos atributos específicos que cada sociedade impõe ao masculino e ao feminino, a partir dos lugares social e cultural construídos hierarquicamente, como relações de poder (SCOTT, 1995). Nessa perspectiva, questiona-se o uso biológicodeterminista do termo "sexo". Entendemos que gênero atravessa a relação trabalho-saúde por apontar a constituição dos processos de trabalho através de relações desiguais de gênero, que tem efeitos diferenciados na saúde de mulheres e de homens trabalhadores (OLIVEIRA, 1997).

Nas entrevistas realizadas com as funcionárias da empresa em questão, quando perguntamos se elas percebiam algum tipo de diferença/desigualdade entre homens e mulheres dentro e fora da empresa, todas responderam que não notavam. Porém, com o avançar das entrevistas, elas relacionavam o turno noturno com as atividades ligadas à reprodução social, apontando algumas disparidades, conforme referiram Paula e Rosa ${ }^{3}$ :

Pelo menos o que eu vejo comentar [entre os funcionários da empresa] é "Ah, dormi o dia inteiro", "Ah, não sei o que”, eu digo "Ah, é fácil, né? Porque [para] nós é diferente!” Eu tenho filho pequeno. Mesmo tendo filho pequeno, a roupa não pula de dentro da máquina, lavada. Eu acredito que seja mais fácil [para os homens] do que para nós (Paula).

Ah, eu não sei, eu não consigo visualizar se para eles era melhor ou não. A única condição que tinha é que a gente conversava sempre entre as meninas, era que as mulheres têm mais responsabilidade, né. Eles [funcionários homens] conseguem descansar mais. (Rosa)

De maneira semelhante, $\mathrm{Bia}^{4}$ relatou a facilidade que os homens encontram no ambiente domiciliar, pois os cuidados com a casa e com os filhos se restringem às mulheres, estando eles mais livres para descansar: "eu acho que tem diferença do homem, chega em casa e dorme".

Com relação ao mesmo assunto, a fala de $\operatorname{Raquel}^{5}$, a mais jovem das entrevistadas, denota a responsabilidade da mulher como cuidadora do lar, possibilitando a reflexão acerca da maneira como ela percebe o "papel da mulher" casada, como responsável pelos cuidados com o marido, funções que ela ainda [só] não exerce por ser solteira:

\section{Ah, pra mim não é tão difícil porque eu não sou casada, não tenho compromisso. Não tenho aquela coisa de chegar e arrumar a roupa do meu marido, sabe? Eu não preciso. Se eu não lavar com certeza minha mãe vai lavar. (Raquel)}

Em consonância com os achados de Araújo, Picanço e Scalon (2007) ressaltamos, das falas, a expressividade de uma jornada intensiva de trabalho feminino, que é assumida socialmente como algo que diz respeito só à mulher. Conforme dados do Ministério da Saúde, as mulheres trabalham durante mais horas do que os homens e, pelo menos, metade do seu tempo é gasta em atividades não remuneradas, que acabam por restringir ainda mais o acesso delas aos bens sociais, inclusive aos serviços de saúde (BRASIL, 2011).

Através das falas, percebeu-se que grande parte das mulheres se vê destinada à realização de tarefas domésticas, e que tais tarefas afetam a sua saúde na medida em que invadem e constrangem o tempo para a realização de outras atividades básicas, como sono, descanso e demais atividades associadas à sociabilidade e ao lazer. Nesse sentido, a fala de Maria ${ }^{6}$ ilustra não só as suas “obrigações” com os afazeres domésticos, quando descreve sua rotina, mas também os reduzidos períodos de sono e de descanso que usufrui:

\section{[...] quinze para as oito eu vou dormir, eu chego sete e dez. Eu durmo até onze e meia. Se eu tenho almoço pronto eu durmo até meio-dia, senão eu tenho que levantar às onze. Dependendo o que eu tenho de almoço pronto... Aí ele [marido] chega tipo meio-dia e dez com o guri do colégio. Aí nesse horário eu estou com o almoço pronto. Daí ele almoça, meu esposo sai para trabalhar e meu guri fica comigo. Aí faço o tema com ele, se ele tem tema. Já pego ele no início, já chegou do colégio já faz o tema porque depois ele fica com preguiça e não quer fazer. Aí depois estuda um pouco, e eu convenço ele a deitar um pouco e ver uma tv, ele acaba dormindo antes que eu [risos]. Porque ele levanta cedo, vai cedo para o colégio, aí eu aproveito e dou um cochilão até umas quatro, quatro e meia, daí já levanto, faço a janta, dou banho nele... (Maria)}

No relato de Rosa, aparece a tensão cotidiana de dedicar mais tempo aos filhos, o cansaço relativo ao turno noturno e ao acúmulo de tarefas:

\footnotetext{
Era ruim pra nós [o turno noturno], puxado. Estava sempre cansada, mas era a única opção pra ficar mais tempo com o filho. E também dava tempo para fazer tudo: ir ao médico, banco. Se precisava dormia menos, mas estava lá, pelo menos. (Rosa)
}

\footnotetext{
3 Paula: 26 anos, filho de 6 anos, é casada, está há 2 anos e meio no turno noturno. Rosa: 34 anos, casada, filho de 11 anos. Trabalhou no turno noturno por cerca de 6 anos.

4 Bia: 38 anos, casada. Grávida de 4 meses; filho de 15 anos. Há 3 anos no turno noturno.

5 Raquel: 21 anos, solteira. Há 3 anos no turno noturno.

6 Maria: 34 anos, casada. Filho de 6 anos. Há 1 ano e meio no turno noturno.
} 
Conforme apontam os estudos, as mulheres encontram maiores dificuldades no mercado de trabalho, tanto por serem mães quanto pela idade dos filhos. Diferentemente dos homens, que, na sua grande maioria, não têm a carreira prejudicada ou modificada pela paternidade. A responsabilidade pelo cuidado e educação dos filhos e a insuficiência de creches, por exemplo, limitam a saída da mulher para o trabalho remunerado, sobretudo se os rendimentos obtidos são insuficientes para cobrir custos com formas remuneradas de cuidado infantil (ROTENBERG, 2004; BRUSCHINI, 2007; FREIRE, 2007).

No trabalho noturno, a presença de algum membro da família que auxilie nos cuidados com o(s) filho(s) é fator determinante para a continuidade (MARCONDES et al., 2003; ROTENBERG, 2004). Foi evidenciado, nas falas das entrevistadas, particularmente das que têm filhos menores de 15 anos, que a presença dos filhos foi, em alguns momentos, um fator motivador para o ingresso no trabalho noturno. Como no caso de Rosa, que atualmente trabalha apenas no sindicato e não mais no turno noturno: "[...] eu optei por ficar nesse turno por isso, pela questão de que eu conseguia estar em casa, meu filho que era pequeno na época. Eu tenho um filho que agora está com 11, era menor, então eu optei por uma forma de eu conseguir ter alguns momentos com ele, né?"

Tal fato se repetiu na entrevista de Bia, que referiu a mesma razão para a incursão noturna como horário de trabalho:

Olha para mim, cada uma tem a sua particularidade, né? Eu vim para o terceiro [turno noturno] porque eu quis acompanhar mais meu filho durante o dia, eu ficaria mais tempo com ele durante o dia. Dá para acompanhar ele no colégio... Ah, e agora como ele já é mais um adolescente, pré-adolescente no caso, eu já fico mais por perto dele, né? Então eu optei pelo terceiro. Para mim foi mais por essa parte. (Bia)

As falas das entrevistadas delinearam uma mulher disposta a alterar sua rotina, a mudar de emprego e/ou reorganizar o tempo de trabalho em prol do cuidado com os filhos, passando por cima de quaisquer formas de saúde física e psicossocial por razões maternas:

Então para nós, mães, é uma coisa sacrificada porque tu tens que arrumar um tempo para dormir, tu não dormes. Barulho do dia para nós às vezes atrapalha. É uma coisa assim que tem vezes que tu estás tão cansada que chega e dorme. Tu chegas e apagas, mas tem vezes que não. É barulho do dia a dia, é vendedor, é tudo, tudo que gera em torno de ti durante o dia só que tu estás dormindo... (Bia)

[...] eu tive a apresentação do meu guri e eu saí daqui no sábado de manhã. Eu tive que ir no centro no sábado de manhã, eu não consegui dormir e à tarde eu tive que ir no colégio porque tinha a apresentação. E não dormi. Aí eu sei que eu fui no centro, voltei, fiz o almoço, fui para apresentação. Não tinha dormido nada. Aí quando chegou cinco horas da tarde o corpo não estava aguentando mais. E parecia que eu tinha tomado... Chapada, né? Porque meus olhos... (Maria)

As dificuldades para conciliar trabalho e família são ainda maiores para as mães de filhos pequenos, não só porque eles requerem maiores cuidados, mas também em decorrência da frágil política pública para atenção às crianças de 0 a 6 anos. De acordo com o levantamento do Tribunal de Contas do Estado do Rio Grande do Sul (TCE-RS), entre 2008 e 2011, o Estado deixou de criar 189 mil vagas para a Educação Infantil, e não cumpriu com as metas do Plano Nacional da Educação (PNE) para o Ensino Infantil. Importante refletir que "[...] a cada 100 crianças de 0 a 3 anos do estado, apenas 23 receberam atendimento em creches, independente da rede. Entre as crianças de 4 a 5 anos, apenas 63 a cada 100 foram atendidas na pré-escola" (INSTITUTO BRASILEIRO DE GEOGRAFIA E ESTATÍSTICA, 2012; RIO GRANDE DO SUL, 2012). Isso indica uma situação de inequidade, em que a falta de assistência às crianças reflete diretamente na ocupação da mãe.

Para suprir essas carências, o que normalmente acontece é que as trabalhadoras contam, quando podem, com a ajuda de terceiros nos cuidados com os filhos, e ficam à mercê de algum auxílio prestado por alguém que mantenha algum vínculo familiar (avó, tia, filha) ou vínculo social (vizinha), ou, ainda, alteram seu trabalho ou suprimem seu descanso (BRUSCHINI, 2007; SCHIRMER, 1997; DEDECCA; RIBEIRO; ISHII, 2009).

É comum que a mulher deixe de trabalhar, reduza o horário de trabalho ou altere o turno em prol do cuidado com os filhos. Porém, muitas vezes, esse contínuo "adaptar a vida aos afazeres domésticos" reitera desigualdades de gênero e acaba por naturalizar a falha dos equipamentos públicos para com a assistência às trabalhadoras e às crianças (OLIVEIRA, 1999; DEDECCA; RIBEIRO; ISHII, 2009; BRUSCHINI, 2007). Uma das entrevistadas expressou que, devido à "ausência" de alguém que cuidasse do seu filho, preferiu reorganizar o horário de trabalho, com a finalidade de atender às exigências da relação mãe e filho:

\footnotetext{
Quando eu vim para o terceiro foi por necessidade, porque eu não tinha quem pegasse meu filho no colégio, porque ele estava saindo da creche, a gente criou ele sempre em creche, aí ele estava indo para o colégio para o primeiro ano e não tinha quem pegasse ele. Eu tentei alguém, ninguém queria aquele pouco tempo que era um horário das cinco às sete horas que meu esposo chega. Ninguém queria trabalhar naquele horário, sabe? Não era de graça, eu ia pagar, mas ninguém queria aquele compromisso daquele horário porque achavam muito pouco tempo. Aí não tinha quem pegasse ele, aí eu optei por trocar de turno. No início foi complicado... (Maria)
} 
A partir desse ponto, a entrevistada relata que não gostou, inicialmente, da mudança. Contudo, ao perceber que o tempo que passava com o filho se tornou maior, passou a enxergá-la como positiva, independentemente do desgaste físico. Essa referência também foi mencionada por Bia: “[...] uma reunião no colégio, pegar ele no colégio, pegar o boletim, participar de alguma coisa que eles apresentam. Isso é muito importante. Faz um pouquinho de sacrifício, dorme um pouquinho menos, mas tu estás sempre lá."

A pesquisa evidenciou que os horários diurnos são ocupados, pela maioria das trabalhadoras, com o descanso (dormir), com afazeres domésticos e com obrigações vinculadas aos filhos. Quando questionadas sobre os períodos de lazer, algumas demonstraram insatisfação com a falta de momentos de distração, referiram que sentem falta de sair em horários "normais", "sem preocupação". Outras, no entanto, demonstraram satisfação nesse aspecto, pois associaram lazer com o cuidado materno.

No que tange à representatividade feminina na empresa estudada, principalmente no turno noturno, os homens ocupam cerca de $90 \%$ dos cargos. No entanto, mesmo se tratando de um setor produtivo majoritariamente masculino, vem acompanhando a tendência mundial de aumento da força de trabalho feminino, e por isso demonstrando maior incremento de mão de obra feminina, ao longo dos últimos anos (SARDENBERG, 2004; ARAÚJO; OLIVEIRA, 2006). Porém, o aumento do trabalho feminino tem sido parte de uma nova forma de trabalho, para a qual as empresas têm se reestruturado por objetivarem produzir mais, obtendo maiores lucros com menores custos (MONTAGNER, 2004; OLIVEIRA, 1999; BRITO, 2000; ARAÚJO; OLIVEIRA, 2006).

As tentativas de modernização e de redução de custos, em boa parte das empresas do setor metalúrgico, têm propiciado o aumento do desemprego, a precarização das condições de trabalho e a flexibilização da jornada de trabalho (OLIVEIRA, 1997; GIANNASI, 1997; DEDECCA; RIBEIRO; ISHII, 2009). Além disso, essa modificação, chamada reestruturação produtiva, aguça ainda mais a desigualdade entre os gêneros. As mulheres são submetidas a funções menos qualificadas, aos trabalhos mais intensificados e aos postos taylorizados, que ainda exigem delas qualidades vistas como essencialmente femininas, como cuidado, paciência, atenção, destreza, além de exigirem a necessidade de realizar atividades repetitivas (GIANNASI, 1997; ARAÚJO; OLIVEIRA, 2006).

A existência de desigualdades pôde ser percebida a partir do discurso de Maria, que demonstrou interesse em se qualificar, mas que, segundo sua avaliação, não alteraria em nada sua situação na empresa:
Eu queria estudar, mas agora com meu filho tenho que dar primeiro atenção para ele. Depois quando ele estiver maior... Ele cresce muito rápido. [...] como esses dias eu ainda pensei, né? Faz falta tu estudar para aprender, mas em relação ao nosso salário não vai mudar. Não vai mudar porque tem tanta gente já formada ali que não ganha a promoção, que às vezes surge uma promoção e eles pegam às vezes um de fora e não pegam do setor que está formado. Aí, tu vais estar deixando teu filho sozinho em casa e estudar para saber que teu salário vai ficar a mesma coisa. Mas é bom para aprender, mas se vai pensar em relação de aumentar o salário... (Maria)

As mulheres do turno noturno da empresa estudada trabalham em apenas um setor, aquele que envolve a distribuição de peças (CDP), e não apresentam perspectivas de plano de carreira, de acréscimo de salário ou de progressão funcional, conforme foi explicitado pelas entrevistadas. Ao questionamento acerca das possibilidades de progressão para os homens, as falas tornam evidentes as desigualdades entre os gêneros. Segundo os relatos, para os homens a qualificação pode gerar novas oportunidades dentro da empresa.

Nessa altura, identifica-se que, apesar de anteriormente as mulheres terem negado qualquer diferença/ desigualdade de gênero, no âmbito da progressão profissional foram apontadas as oportunidades que os homens dispõem dentro da empresa, e que elas não possuem. Tais dados conferem com os estudos já existentes, constatando que, mesmo alguns homens dividindo as mesmas funções que as mulheres, eles têm a chance de ocupar cargos que exigem conhecimentos mais técnicos e científicos, áreas mais modernas e tecnológicas, funções de chefia e de liderança, conquistando, portanto, melhores salários; já as mulheres não vivenciam as mesmas perspectivas de trabalho (GIANNASI, 1997; BRITO, 2000, 2011; ARAÚJO; OLIVEIRA, 2006).

A divisão do trabalho pautada nas relações desiguais de gênero atravessa a reestruturação produtiva, implicando a coexistência de um setor flexibilizado masculino e de um setor taylorizado feminino. Porém, a maioria dos estudos de análise da reestruturação produtiva acaba por apontar os aspectos positivos, dando ênfase ao trabalhador moderno, polivalente e qualificado, "esquecendo" que as mulheres não têm sido requalificadas para os novos equipamentos de base microeletrônica, e nem têm sido contempladas com aperfeiçoamentos técnicos, nem maiores rendimentos (BRITO, 2000; HIRATA; KERGOAT, 2007). Em suma, o trabalho das mulheres nas indústrias é caracterizado pela repetitividade, monotonia e pelo ritmo intenso, sem obterem melhores oportunidades (BRITO, 2000).

No que se refere ao sindicato de metalúrgicos da região pesquisada, embora agregue homens e mulheres, a maioria é masculina. A representatividade 
das trabalhadoras noturnas é ainda menor por esse turno ser ocupado quase que totalmente por homens. O processo de transformação da estrutura sindical e a incorporação política das mulheres nas estruturas de poder ainda não são suficientes para garantir a igualdade de tratamento, nas relações de trabalho e nas relações sindicais, entre mulheres e homens (COSTA, 2004). As vivências de trabalhadoras metalúrgicas em relação ao sindicato ainda estão permeadas pela exclusão feminina e pelos tratamentos sexistas (SARDENBERG, 2004).

No presente estudo, a maioria das entrevistadas confirmou a importância da existência do sindicato. No entanto, transpareceu, nas falas, o desconhecimento e, ainda, o acesso restrito aos direitos trabalhistas, que poderiam ser mais bem mediados pelo sindicato, bem como a reduzida representatividade feminina, uma vez que as reivindicações são mais pensadas para os trabalhadores do que para as trabalhadoras.

\section{A saúde das trabalhadoras na penumbra: reflexões sobre vulnerabilidades}

Neste tópico, articulamos as falas analisadas com a reflexão de Ayres et al. (2009) sobre a produção de vulnerabilidades em saúde, e com as considerações sobre os efeitos das desigualdades de gênero nos processos de saúde-adoecimento.

Ao considerar as vulnerabilidades, chamamos atenção para o "[...] conjunto de aspectos individuais e coletivos relacionados ao grau e ao modo de exposição à dada situação e, de modo indissociável, ao maior ou menor acesso a recursos adequados para se proteger das consequências indesejáveis daquela situação" (AYRES et al., 2009, p. 123). Destacam-se os aspectos da produção de vulnerabilidades que dizem respeito às dimensões individual, social e programática, para pensar a relação gênero/trabalho/saúde. Consideram-se, no plano individual, as percepções e as maneiras de agir de acordo com os saberes e as possibilidades com as quais contam os sujeitos. No plano social, referimos às práticas coletivas de enfrentamento às adversidades, conforme a disponibilidade de recursos e ao acesso a esses recursos. E no plano programático, pensamos a falta de investimentos em ações e programas, serviços sociais e de saúde de fácil acesso, com alta qualidade, democraticamente delineados; assim como a falta de adoção de mecanismos de não discriminação nas instituições.

Em relação aos resultados do estudo, no plano individual das vulnerabilidades, pode-se notar que as entrevistadas encontram uma série de adversidades. Pode-se ressaltar o cansaço e a falta de sono decorrentes do acúmulo de tarefas no cotidiano, para além do âmbito de trabalho, como o principal diferencial causado pelo turno noturno.

Em muitos momentos, elas se referiram à privação do sono, à dificuldade ou ao pouco tempo para dormir, aos barulhos do dia e aos afazeres que comprometem o tempo de descanso. O sono não é o mesmo do que aquele realizado à noite: "não é um sono reparador", como enfatiza uma entrevistada. Reportaram-se à dificuldade em "pegar no sono", ao chegar a casa, devido às características do período diurno (barulho intenso), assim como às "obrigações" a elas imputadas. As trabalhadoras também relataram que, muitas vezes, se sentem agitadas, e por isso não conseguem dormir - fato já descrito como relativo às alterações fisiológicas do organismo referentes ao turno noturno, e que podem gerar adoecimentos que comprometem a saúde em geral (AVENDAÑO; GRAU; YUS, 1997; RÉGISFILHO, 2002; MARCONDES et al., 2003; MORENO; LOUZADA, 2004; ROTENBERG, 2004; FISCHER; LIEBER, 2007; RIBEIRO, 2008; MACAGNAN, 2010).

Quanto a esse aspecto, Maria relatou:

É que às vezes as pessoas sabem que tu trabalhas à noite, mas as pessoas não respeitam. Às vezes elas vêm trovar na frente da tua casa, sabem que tu estás dormindo. Geralmente, no inverno é ótimo que tu não vês ninguém na rua. Agora dá uma esquentadinha e todo mundo vai para a rua. Aí, é aquela barulheira. Tem dias que eu não durmo à tarde, só aquele soninho da manhã. Às vezes, eu deitei quinze para as oito e eu tive um sono só até meio-dia. E acordei renovada. Entende? O problema é que às vezes o telefone toca, aí tu te levantas para atender, porque o convencional é lá... Aí não é nada, aí tu te irritas. À tarde quando eu deito, eu estou acostumando tirar do gancho, que daí eu consigo dormir. Pela manhã não posso, vai que acontece alguma coisa com meu guri, mesmo tendo o celular, não fico tranquila. Aí às vezes toca o telefone, tu vais atender e é besteira, te oferecendo pacote... Aí tu já acordaste, para voltar tudo de novo. (Maria)

Cabe ressaltar que as percepções sobre as dificuldades e adversidades relativas ao turno de trabalho foram sendo expressas ao longo das entrevistas, já que, inicialmente, elas não reportavam quaisquer incômodos. Outra queixa foi referente às alterações fisiológicas geradas pelo turno noturno, e também a repercussão que isso pode gerar em âmbitos individual e social:

É que o sono do dia não é o mesmo que o sono da noite, né? Então o que acontece, que assim como as outras também, chega fim de semana, principalmente no sábado que tu não vais trabalhar tu passas a noite acordada... (Vera $\left.{ }^{7}\right)$

No final de semana quando tu queres aproveitar tipo como todo mundo, então no tempo que tu tens para ficar com a tua família, tu estás desmaiando. Que nem eu no final de semana que eu deitei às três horas de

\footnotetext{
Vera: 45 anos, casada. Filho de 15 anos. Há 5 anos na empresa e há 4 no turno noturno.
} 
domingo e acordei às dez da noite. Quando estava todo mundo querendo dormir eu estava bem ligada querendo conversar... (Raquel)

Interessante trazer à luz a condição de trabalho vivenciada por Dulce ${ }^{8}$, vigilante noturno, que enfrenta intensa pressão psíquica por precisar estar em constante estado de alerta, pois porta arma de fogo e cuida da segurança da empresa. Além disso, agrega maior jornada de trabalho (12 horas) e, segundo ela, "[...] não tem feriado nem final de semana. É sempre um dia sim um dia não". Ela também relata estar estressada e com dificuldades para dormir:

Eu até durmo durante o dia. Eu deito quando eu chego de manhã, mas na minha noite de folga eu não consigo dormir. Eu tenho mal-dormir. Quando eu consigo dormir é um mal-dormir horrível. E ultimamente eu não consigo, não estou conseguindo dormir de dia também. Eu agora mesmo eu estou... Acho que dois dias que eu não consigo dormir. Não sei se é estresse, acho que é... Vai cansando. Acho que é o estresse. Amanhã de manhã eu vou na empresa lá e eu quero pedir alguma coisa para me ajudar a relaxar. [...] Eu preciso trabalhar. Sábado eu não consegui vir. Cheguei no meu limite. Fazia muitas e muitas horas, aí eu comecei a ter tontura. Aí não vim trabalhar. (Dulce)

Um ponto que merece atenção é de caráter hormonal. Por estarem acordadas em um período em que o corpo habitualmente estaria em repouso, alguns hormônios não reagem da mesma forma, bem como o sistema digestivo dessas mulheres, comprometendo sua saúde e seu bem-estar. Associando isso à má alimentação, podem ser gerados agravos físicos, ou propiciado o agravamento de algumas doenças (CRISTOFOLETTI, 2003; ASSIS; MORENO, 2004; FISCHER; LIEBER, 2007; MACAGNAN, 2010).

Através das entrevistas, algumas irregularidades puderam ser percebidas nas refeições das trabalhadoras, tanto na qualidade quanto na quantidade dos alimentos consumidos. No que tange às limitações relativas aos horários das refeições, também há dissonâncias: como ocorrem em horário não usual, se comparadas com a de grande maioria dos trabalhadores, algumas tinham o hábito de "beliscar alguma coisa", ao invés de jantar, ou não "tinham apetite” no horário em que era servida a janta da empresa, por acharem estranho fazer uma refeição tão tarde.

A aglutinação das alterações metabólicas com a fragilidade alimentar torna as trabalhadoras mais suscetíveis ao desenvolvimento de algumas doenças, como hipertensão, patologias cardíacas, dislipidemias, alterações hormonais, transtornos do apetite, gastrite crônica, sobrepeso, obesidade, diabetes e outros acometimentos que geram uma piora na qualidade de vida dessa população (MORENO; LOUZADA, 2004; COSTA, 2004; BARRETO, 2008; MACAGNAN, 2010).

No presente estudo, foi possível perceber que algumas entrevistadas estavam com excesso de peso. Além disso, no decorrer das entrevistas, algumas mulheres relataram desconforto com o peso, e apontaram o turno noturno como fator potencializador desse problema. Alice ${ }^{9}$, além de afirmar seu excesso de peso, também apontou outras funcionárias do turno noturno como tendo adquirido peso:

Eu já estava gordinha, mas eu percebi que eu ganhei mais peso, porque na verdade assim eu não sou muito magra. A Teresa e a Raquel são um caso à parte, mas se tu olhar a maioria das mulheres tão todas bem fortinhas. Daí eu percebo assim, que eu nunca fui uma pessoa muito de atividade física, mas eu noto que eu estou muito mais sedentária... (Alice)

Outro aspecto impactante à saúde das trabalhadoras, relacionado com a alimentação, foi expresso por Vera, visivelmente com obesidade, que relatou ser hipertensa e se sentir infeliz com seu peso. A entrevistada pretendia se submeter à cirurgia bariátrica, objetivando reduzir o peso e melhorar a qualidade de vida. No entanto, o médico não aceitou operá-la, porque entendeu não ser seguro submetê-la ao procedimento devido ao turno de trabalho e às responsabilidades exigidas no pós-operatório:

\begin{abstract}
Até eu ia fazer a cirurgia bariátrica. Mas daí o médico ficou muito preocupado por causa do meu horário de trabalho. Porque tudo é regrado [no pós-operatório]. Tem horário para se alimentar... Várias coisas... Aí o horário que eu trabalho ele ficou muito preocupado. A única coisa que tem em relação à cirurgia era o horário mesmo. Até eu fiquei meio assim... [...] mas daí eu estou pensando seriamente... Se é para arrumar uma coisa e estragar outra, né? (Vera)
\end{abstract}

Faz-se interessante ressaltar que Dulce, aparentemente também com sobrepeso, embora já tenha realizado a citada cirurgia há alguns anos antes de aderir ao turno noturno, faz menção às dificuldades alimentares que enfrenta. Ela se refere ao fato de, por vezes, precisar se alimentar rapidamente, devido às pressões do horário de trabalho, o que a faz sentir alguns desconfortos:

Eu particularmente antes, eu fiz uma cirurgia de redução de estômago há oito anos. Oito anos atrás. Eu tinha $150 \mathrm{~kg}$. Ninguém diz. Tu sabes que eu me alimento muito mal, que eu não como carne, eu tenho que comer devagarinho. Então eu como quase nada, me alimento muito ruim, tenho que estar sempre tomando vitamina. É bem complicado. Se eu vou lá e janto correndo e volto correndo, chega dez para às três da manhã, que é a saída da empresa, eu chego aqui já não para no estômago. Para mim é complicado. (Dulce)

\footnotetext{
8 Dulce: 37 anos, casada. Uma filha com 14 anos e outra com 19 anos. Há 1 ano e meio no turno noturno da empresa.

9 Alice: 45 anos, casada. Filho de 24 anos. Na empresa, há 15 anos, e há 1 ano e meio no turno noturno.
} 
$\mathrm{Na}$ fala das entrevistadas, foram identificadas queixas de dores no corpo por esforços repetitivos, relacionadas não só ao cansaço, mas também ao tipo de atividade desenvolvida, conforme a função que ocupam na área de conferência. É o caso de Teresa ${ }^{10}$, que já ficou "de atestado" por um tempo devido às dores. Ela trabalha na conferência, setor que exige a execução de movimentos físicos repetitivos, e é considerado, segundo as trabalhadoras, "um trabalho bastante pesado e manual”.

Raquel exerce a mesma função, e mencionou mais problemas físicos do que Teresa, ainda que seja mais jovem: “[...] tenho duas hérnias de disco, tenho escoliose, tenho tendinite, tenho bursite, tenho síndrome do carpo". Ao ser questionada sobre as possíveis causas das doenças, ela indica a condição de vulnerabilidade vivenciada, reforçando a gravidade que essa forma de trabalho pode gerar a longo prazo: “[...] eu não tinha, eu adquiri tudo aqui dentro. Eu trabalho na área da conferência, no caso. Na separação não tem esforço repetitivo porque tu fica caminhando, né. Agora, na conferência, tu tem que ficar conferindo o que vem." (Raquel)

Vera, que trabalhava no mesmo setor, relembra que pediu para alterar sua função devido às dores relativas ao trabalho, ilustrando também a dificuldade de consultar o médico da empresa (devido ao turno noturno), além dos acometimentos à saúde relativos ao tipo de trabalho:

Agora eu estou trabalhando nos kits, é mais tranquilo. Eu trabalhava na conferência e vivia em tratamento, em terapia, não dava mais. Aí tinha que estar faltando sempre porque o médico que trabalha aqui ele não atende em outro horário. Tu tens que ter o teu cartão [da empresa], aí não dava. (Vera)

Pesquisas mostram que as mulheres constituem o grupo mais atingido, no trabalho, por doenças e por lesões osteomusculares relacionadas ao esforço repetitivo (LER/DORT). O setor industriário é o maior responsável por esses processos. Nessa faixa incluem-se as metalúrgicas, devido, principalmente, à concentração de mulheres nas linhas de montagem e nos postos marcados pelo ritmo intenso e por tarefas repetitivas (BARRETO, 1997; OLIVEIRA; 1999; BRITO, 2000; ARAÚJO; OLIVEIRA, 2006).

As entrevistadas expressaram vivências que podem ser relacionadas à noção de sofrimento mental, tratado como uma experiência vivida no cotidiano que incide na qualidade de vida. O sofrimento mental não necessariamente se converte em um estado patológico permanente, mas pode vir a se tornar, a partir das experiências: uso do tempo dentro e fora do trabalho como estruturante do sofrimento; ausência de qualificação, provocando sentimento de inutilidade; e ausência de finalidade do trabalho. "Se o trabalhador não pode pensar sobre as tarefas, a relação construída com o processo de produção será sempre uma relação de inutilidade e alienação" (DEJOURS apud OLIVEIRA, 1999, p. 79). Tais fatores impactam a saúde e se tornam ainda mais deletérios quando fundados sobre a margem da desigualdade de gêneros. Esse sofrimento é definido pelas próprias trabalhadoras entrevistadas como estresse, ainda que não relatado literalmente, mas manifestado por meio de outras formas de expressão.

Como mostram os estudos epidemiológicos, as trabalhadoras noturnas estão sujeitas, diariamente, a uma gama de aspectos que podem acarretar episódios de sofrimento e adoecimentos, já que as alterações de humor são, muitas vezes, reações do organismo ao estresse, que pode ser oriundo das mudanças nos horários de sono e na falta de descanso (BARRETO, 2008).

Além disso, entre os potenciais impactos à saúde estão: o ambiente de trabalho, o turno de trabalho; o reduzido tempo de sono e de repouso, o horário do descanso e as intercorrências no período diurno; os hábitos alimentares dentro e fora da empresa; a realização de atividades domiciliares; o constrangimento do tempo de lazer, o isolamento social e muitos outros aspectos, todos em concomitância, propiciando o acúmulo de penosidades (ROTENBERG, 2004; OLIVEIRA, 2005). Relaciona-se um relato sobre o desconforto e a insatisfação que a supressão e a inversão dos tempos de socialização e lazer podem gerar:

\begin{abstract}
Minha questão, família, no caso, é complicada porque tu trabalhas no terceiro [turno noturno], aí tu ficas sempre diferente dos outros. Se alguém combina para sair, né? Porque geralmente no verão todo mundo quer sair. A partir das seis horas todo mundo está em casa: "Ah, a Bia tem que trabalhar", "Aí, vamos marcar outro dia porque a Bia tem que trabalhar". Aí a gente fica... [pausa] Mas tranquilo, eles aceitam numa boa, sabe? Principalmente meu marido e o Pedro, meu filho, a gente nota que eles queriam que a gente tivesse presente. (Bia)
\end{abstract}

Possivelmente, de todos os impactos à saúde, talvez os problemas relativos ao sofrimento mental (estresse, tensão, irritabilidade, depressão) sejam os mais limitantes, pois, além de serem "invisíveis", estão relacionados com todos os outros processos que podem ser gerados a partir da relação gênero e trabalho noturno (REGIS-FILHO, 2002; MARCONDES et al., 2003; MORENO; LOUZADA, 2004; ROTENBERG, 2004).

Neste artigo relacionamos tais agravos à saúde com a divisão do trabalho pautada em relações desiguais de gênero, bem como apontamos a relação

\footnotetext{
10 Teresa: 30 anos, casada. Sem filhos. Trabalha na empresa há 3 anos, sempre no turno noturno.
} 
desses agravos com a piora na qualidade de vida dessas trabalhadoras, com as vulnerabilidades sociais produzidas por desigualdades de gênero decorrentes da responsabilização gerada pela dupla jornada de trabalho e pela falta de descanso devido ao horário noturno.

Quanto à dimensão social de produção de vulnerabilidades, ressalta-se, aqui, o acúmulo de tarefas na organização dos afazeres domésticos decorrentes de relações de gênero desiguais. Com relação ao cuidado dos filhos, destacamos a não disponibilidade de creche como equipamento social para trabalhadoras de turno noturno, tendo que ser mobilizadas redes de apoio na família e, ainda, estratégias já referidas das mulheres para organizar esses cuidados.

Agregando às relações de gênero o trabalho realizado à noite, tornam-se mais substanciais as vulnerabilidades devido à diferente forma de organizar o dia, que tende a ser mais complexa para as mulheres, conforme discutimos anteriormente, propiciando a intensificação das cobranças físicas e mentais.

Raquel foi uma das trabalhadoras que verbalizou estresse, ao responder como seu namorado reagia ao turno em que ela trabalha:

\begin{abstract}
O meu namorado já sofreu mais... Agora ele está mais, assim... O meu problema é com estresse, sabe? Depois que eu passei para o turno da noite, depois que eu comecei a trabalhar à noite eu percebi que eu fiquei muito mais estressada do que eu já era, quer dizer, não sei se eu era. Eu era alegre, sabe? Têm dias que eu estou, assim, que não podem me falar um ai... (Raquel)
\end{abstract}

Sobre o questionamento acerca da razão do estresse, Raquel o relaciona com a falta de convívio social e de lazer, questões que aparecem em estudos que os apontam como geradores de mais insatisfação e de intolerância ao trabalho, além de promoverem irritabilidade e outras questões psicológicas, para além da falta de descanso e das limitações do sono (OLIVEIRA, 2005; ARAÚJO; OLIVEIRA, 2006). A entrevistada relatou, ainda, que recebe atendimento psiquiátrico:

Eu não sei se pelo sono. Eu me trato com uma médica, e ela diz que é pelo meu horário mesmo. Eu não participo, eu adoro esse turno, mas querendo ou não eu não participo da vida da minha família. Só nos finais de semana... [...] Eu tenho convivido muito mais, claro com todo mundo, né? Mas quem eu converso mesmo, quem eu passo mais tempo acordada é com o pessoal da empresa. E é onde eu estou menos estressada, porque eu estou saindo de casa e eu estou... Nossa! Sabe? Com muita raiva! Quando eu chego aqui começa a passar, começo a melhorar. Teve uma época pior, antes nem queria voltar para casa, mas agora está bem menos... Agora eu já estabilizei... (Raquel)
Raquel, a mais nova do grupo, reside com a mãe, e, conforme já exposto, não tem filhos. Diferentemente de Paula, que tem um filho de 6 anos, mora com o marido e divide o terreno onde está sua casa com sua mãe. Mesmo Paula contando com a ajuda da mãe, ainda assim enfrenta maiores atribuições domésticas do que Raquel, cujo estresse decorre do isolamento social gerado pelo turno de trabalho. Paula, além de dispender mais tempo com os afazeres domésticos, também enfrenta o turno noturno, e descansa ainda menos do que Raquel. Conforme anteriormente citado, Paula também está insatisfeita com o reduzido período de lazer:

Depois que eu vim para a noite eu fiquei mais
preocupada, tudo para mim estava bom, agora está
tudo ruim, sabe. Muito ruim. Eu estava acostumada
a trabalhar em comércio, é tudo diferente, sempre
uma coisa diferente. Aqui é todo dia mesma coisa,
sabe? Fechado. Aí tu vais para a rua, olha o céu...
Preto, sabe? Sempre aquela mesma rotina. Até estou
adorando. Eu nunca imaginei trabalhar num lugar
fechado, à noite, mas tu não vive. Tu aproveitas mais,
tu curtes teu filho, mas tu não vives. Enquanto está
todo mundo acordado tu estás lá dormindo, quando
está todo mundo dormindo tu estás lá acordada. (Paula)

As constantes menções ao estresse gerado a partir das jornadas de trabalho merecem atenção. Conforme estudo epidemiológico (DORNELLES; LEHFELD; ENGLER, 2010), as mulheres que trabalham fora de casa e são responsáveis pelos cuidados de crianças e de idosos estão mais propensas a desenvolverem depressão. Além disso, ainda segundo esse estudo, mostraram-se mais vulneráveis aquelas em extremidades econômicas, ou seja, as que ocupam melhores cargos e as de baixa renda. Sendo assim, a situação familiar (presença ou não de parceiro, presença ou não de filho(s), presença de filho(s) com parceiro, presença de filho(s) sem parceiro; apoio social; e atitude positiva do cônjuge ou companheiro(a) em relação ao turno de trabalho da mulher) pode vir a ser característica determinante no processo de tolerância e de adaptação ao trabalho noturno, podendo ou não ser desencadeadora de sofrimento psíquico (OLIVEIRA, 1999; MARCONDES et al., 2003; ROTENBERG, 2004). O mesmo estudo de Dornelles, Lehfeld e Engler (2010) demonstrou que as mulheres com cônjuge e filho(s) são as que mais dedicam tempo aos afazeres domésticos, quando comparadas às solteiras. Portanto, sofrem mais com a jornada fora do local de trabalho, o que confirma os achados encontrados nesta pesquisa.

Ao questionar algumas das entrevistadas com filhos sobre a possibilidade de continuar no trabalho noturno, se não tivessem apoio ou auxílio de alguém no cuidado com os filhos, todas referiram que seria inviável, e que possivelmente não trabalhariam no turno noturno. Ressalta-se, mais uma vez, a tensão e preocupação agregada à relação turno-filho(s) e 
a falta de amparo social às trabalhadoras. Muitas vezes, nas falas, essas situações apareceram como obstáculos, mas elas demonstraram modos de lidar compensatórios. Por exemplo: dedicar mais tempo para os filhos; visto como responsabilidade atribuída à mulher, mas também como algo desejável e positivo.

Apesar das queixas e das suscetibilidades, algumas entrevistadas demonstraram satisfação com o fato de estarem trabalhando, pois, mesmo com as adversidades nas formas de organização dos tempos, elas ainda preferem trabalhar a ficar em casa. Como notam outros estudos (OLIVEIRA, 1997, 1999; SARDENBERG, 2004; DORNELLES; LEHFELD; ENGLER, 2010), além da contribuição econômica, elas se sentem mais respeitadas e mais valorizadas pelos próprios cônjuges por estarem trabalhando remuneradamente, ainda que isso signifique uma constante batalha com os afazeres domésticos.

Se focarmos no plano programático da produção de vulnerabilidades, foram destacados, nas falas, vários aspectos, em relação à empresa, que as deixam, assim como aos trabalhadores, “desprotegidas", por exemplo: usufruto de ginástica laboral, que, embora a empresa ofereça, nem todos participam; dificuldade de consultar o médico da empresa; alimentação insatisfatória, particularmente para os trabalhadores do turno noturno. Tais dificuldades institucionais tornam-se mais aprofundadas quando incluímos a dimensão de gênero.

Notoriamente, a maioria das empresas, hoje em dia, faz uso de estratégias que possam minimizar ou evitar agravos à saúde do(a) trabalhador(a) (BARRETO, 1997; OLIVEIRA, 1999; ARAÚJO; OLIVEIRA; 2006), já que quanto mais ele adoece, maiores são as chances dele ficar afastado do trabalho, comprometendo a produtividade.

A empresa em evidência oferece área de recreação e de ginástica laboral aos funcionários como mecanismos destinados a evitar a aquisição das LER, bem como de outros adoecimentos. Teresa refere gostar da atividade: “[...] tem aqui também a ginástica laboral... Eu gosto, venho todo dia. Não é assim um exercício, mas é bom pra relaxar!" Porém, se considerarmos as frequentes referências das entrevistadas aos agravos à saúde, esse empreendimento aparece como limitado.

Conforme citado, na empresa estudada, os homens desenvolvem os mesmos serviços que as mulheres, portanto todos estão sujeitos aos mesmos acometimentos à saúde. Contudo, tendo por base o conteúdo das entrevistas, foi ressaltado que eles possuem um diferencial, que é a chance de mudar e de evoluir de setor, enquanto que às trabalhadoras cabe apenas a troca de função, podendo ser substituídas por um trabalhador, sendo que o contrário não acontece. Retoma-se, então, a questão da qualificação profissional como fator de aguçamento das desigualdades de gênero, e como promotora de sofrimentos mentais, como, por exemplo, através do sentimento de inutilidade e incapacidade profissional. Configura-se, desse modo, mais um aspecto programático de produção de vulnerabilidades em torno do gênero.

Um aspecto unânime relatado pelas entrevistadas foi em relação à qualidade da refeição servida pela empresa. Segundo elas, a refeição parece ser constituída por "sobras" das refeições dos outros turnos e, por vezes, algumas delas não têm vontade de comer. Percebem-se vulnerabilidades decorrentes da falta de serviço adequado quanto à alimentação oferecida no âmbito da empresa. "Eu e a Paula, sabe, a gente almoça na mesma mesa. Aí a gente só se olha, 'hoje tá feia a coisa', aí eu já pego mais uma fruta. Eu tento pegar alguma coisa que eu vá comer depois”; diz Bia em entrevista.

Maria referiu-se à alimentação como "ruim", e acrescentou que, para as mulheres, isso não é tão importante quanto para os homens. Deixando, então, transparecer que os homens teriam certa prioridade no que concerne à alimentação em relação às mulheres, demonstrando a desigualdade de gênero já naturalizada, e ainda denotando a invisibilidade que esses funcionários experimentam através da pobreza alimentar:

\begin{abstract}
Não digo que eu janto aqui, às vezes eu só pego a carne e a salada. Porque às vezes a comida não tá $100 \%$. A nossa janta é pior do que nos outros turnos. A nossa janta é o tipo "soborô". Nossa! Tem dias que não dá. A salada tu olhas e dá nojo só de olhar por cima, ou está murcha ou está preta. Não é que a gente está reclamando, sabe? Nós não é tanto, mas os guris principalmente, né?É isso o que eu penso, que a gente ouve dos nossos colegas "Bah, eu não aguento". Tem uns que dormem direto, comem um pão e vêm para cá, então a janta, o principal deles é ali, aí chegas e te deparas com aquela comida, né? A janta deles, a comida de sal deles que eles vão comer é aquela ali. Do dia todo. Não tem uma verdura nova... (Maria)
\end{abstract}

Cabe ressaltar que a empresa localiza-se em uma região distante de qualquer comércio, tendo somente uma lancheria interna, que funciona até as 22 horas, além do refeitório, que vende apenas salgadinhos de pacotes, refrigerantes e biscoitos recheados.

A alimentação é um direito de todos, e deveria ser mais bem considerada para as(os) trabalhadoras(es), independentemente do horário e do gênero, ainda mais no turno noturno, pois alguns trabalhadores e trabalhadoras preferem dormir durante o dia, e só realizar a principal refeição na empresa. É importante destacar que Bia estava entrando no terceiro mês de gravidez, quando entrevistada, e ressaltou estar passando por um período em que sentia muito enjoo durante o dia, apresentando mais apetite no horário noturno, o que dificultava, ainda mais, sua alimentação na empresa. 
Considerando em contexto mais amplo, percebe-se que os direitos à saúde das trabalhadoras de turno noturno, e ainda no setor metal-mecânico, acabam sendo determinados por legislações universalizantes, que não abrangem a dimensão das relações de gênero na produção e na reprodução social, acabando por tornar invisível a esse segmento da população. Questiona-se, ainda, o acesso dessas mulheres aos serviços de saúde, sendo que foram amplamente referidos os processos de adoecimento, que parecem não ter visibilidade nas ações em saúde, incluindo, aqui, também as práticas preventivas.

\section{Considerações finais}

O presente artigo buscou compreender a imbricação das dimensões sociais que afetam os processos de saúdeadoecimento das trabalhadoras de turno noturno, no setor metal-metalúrgico, entendendo a experiência de saúde dessas mulheres através de diversos aspectos da vida perpassados pelas relações de gênero.

Do conjunto dos aspectos analisados, foram visualizadas situações de vulnerabilidade que podem condicionar a qualidade de vida e a saúde das trabalhadoras, tais como: processo de subvalorização do trabalho, sendo nula a progressão funcional; aguçada jornada laboral, tanto pela busca por melhores condições de sobrevivência familiar (trabalho produtivo remunerado, trabalho doméstico de cuidado das crianças e do lar) quanto pelo turno de trabalho propriamente dito (descanso limitado, alimentação irregular, dificuldades na organização da vida fora do ambiente de trabalho); falta de acesso a suportes sociais que apoiem as atividades femininas.

Todas as participantes da pesquisa evidenciaram a sobrecarga das responsabilidades assumidas, que, muitas vezes, causam sofrimento mental e/ou outros adoecimentos. No entanto, algumas entrevistadas relataram gostar desse turno, pois conseguem passar mais tempo com os filhos, mesmo que descansando menos e restringindo o tempo de lazer. Ainda, percebeuse que a atuação no mercado de trabalho formal e o respeito gerado por isso criam possibilidades de empoderamento a essas mulheres.

Nesse sentido, o estudo verificou algumas afinidades com os estudos que problematizam a relação gênero/ trabalho/saúde, e aportou à discussão especificidades das vivências de trabalhadoras de turno noturno do local pesquisado. Aponta-se que as desigualdades de gênero impactam nas condições de saúde das trabalhadoras metalúrgicas de turno noturno. Esses aspectos devem ser mais bem discutidos na esfera pública. Responsabilidades com a promoção da saúde das trabalhadoras devem ser assumidas, para que se alcance equidade com a melhora das condições de trabalho, no sentido de possibilitar que as mulheres exerçam sua cidadania de maneira democrática e construtiva. Para tanto, é preciso atuar de forma intersetorial, com respaldo nas vivências das trabalhadoras, visando o fortalecimento de ações da sociedade civil organizada e a formulação de políticas públicas nesse âmbito.

\section{Contribuições de autoria}

As duas autoras participaram do delineamento do estudo, da análise dos dados e da elaboração do artigo. A primeira autora realizou a pesquisa de campo.

\section{Referências}

ALMEIDA FILHO, N.; CASTIEL, L. D.; AYRES, J. R. Riesgo: concepto básico de la epidemiología. Salud Colectiva, Lanús, v. 5, n. 3, p. 323-344, 2009. http:// dx.doi.org/10.1590/S1851-82652009000300003.

ARAÚJO, A. M. C.; OLIVEIRA, E. M. Reestruturação produtiva e saúde no setor metalúrgico: a percepção das trabalhadoras. Sociedade e Estado, Brasília, v. 21, n. 1, p. 169-198, 2006. http://dx.doi.org/10.1590/ S0102-69922006000100009.

ARAÚJO, C.; PICANÇO, F.; SCALON, C. Gênero, família e trabalho: Conservadores e satisfeitos? In: ARAÚJO, C.; PICANÇO, F.; SCALON, C. (Orgs.). Novas conciliações e antigas tensões? Gênero, família e trabalho em perspectiva comparada. Bauru: Edusc, 2007, p. 269-328.

ASSIS, M. A. A.; MORENO, R. C. Nutrição entre trabalhadores em turnos e noturno. In: FISCHER, F. M.; MORENO, C. R. C.; ROTEMBERG, L. (Orgs.). Trabalho em turnos e noturno na sociedade 24 horas. São Paulo: Atheneu, 2004, p. 99-114.

AVENDAÑO, C.; GRAU, P.; YUS, P. Riscos para a saúde das enfermeiras do setor público no Chile. In: OLIVEIRA, E. M.; SCAVONE, L. (Orgs.). Trabalho, saúde e gênero na era da globalização. Goiânia: Editora AB, 1997, p. 115-135. 
AYRES, J. R. C. M. et al. O conceito de vulnerabilidade e as práticas de saúde: novas perspectivas e desafios. In: CZERESNIA, D.; FREITAS, C. M. (Orgs.). Promoção da saúde: conceitos, reflexões, tendências. Rio de Janeiro: Fiocruz, 2009, p. 121-144.

BARRETO, M. Lesões por esforços repetitivos (LER): Que danos causam no cotidiano das mulheres. In: OLIVEIRA, E. M.; SCAVONE, L. (Orgs.). Trabalho, saúde e gênero na era da globalização. Goiânia: Editora AB, 1997, p. 87-100.

BARRETO, V. Implicações do trabalho por turnos na saúde e na vida social e familiar dos trabalhadores de turnos industriais. 2008. 115 f. Trabalho de Conclusão de Curso (Licenciatura em Enfermagem)-Curso de Enfermagem, Universidade Fernando Pessoa, Ponte de Lima, Portugal, 2008.

BRASIL. Ministério da Saúde. Política Nacional de Atenção Integral à Saúde da Mulher: Princípios e Diretrizes. Brasília, 2011.

BRITO, J. C. Enfoque de gênero e relação saúde/ trabalho no contexto de reestruturação produtiva e precarização do trabalho. Cadernos de Saúde Pública, Rio de Janeiro, v. 16, n. 1, p. 195-204, 2000. http:// dx.doi.org/10.1590/S0102-311X2000000100020. PMid:10738164

BRITO, J. C. Trabalho e saúde soletiva: o ponto de vista da atividade e das relações de gênero. Ciência $\mathcal{E}$ Saúde Coletiva, Rio de Janeiro, v. 10, n. 4, p. 879-890, 2005. http://dx.doi.org/10.1590/S141381232005000400012.

BRITO, J. C. A ergologia como perspectiva de análise: a saúde do trabalhador e o trabalhador em saúde. In: MINAYO-GOMEZ, C.; MACHADO, J. M. H.; PENA, P. G. L. (Orgs.). Saúde do trabalhador na sociedade contemporânea. Rio de Janeiro: FIOCRUZ, 2011, p. 479-494.

BRUSCHINI, C. Trabalho doméstico: inatividade econômica ou trabalho não remunerado? In: ARAÚJO, C.; PICANÇO, F.; SCALON, C. (Orgs.). Novas conciliações e antigas tensões? Gênero, família e trabalho em perspectiva comparada. Bauru: Edusc, 2007, p. 21-58.

BUSS, P. M. Promoção da saúde e qualidade de vida. Revista Ciência \& Saúde Coletiva, Rio de Janeiro, v. 5, n. 1, p. 163-177, 2000. http://dx.doi.org/10.1590/ S1413-81232000000100014.

COSTA, G. Saúde e trabalho em turnos e noturno. In: FISCHER, F. M.; MORENO, C. R. C.; ROTEMBERG, L. (Orgs.). Trabalho em turnos e noturno na sociedade 24 horas. São Paulo: Atheneu, 2004, p. 79-98.

CRISTOFOLETTI, M. F. Avaliação do estado nutricional de operadores de telemarketing submetidos a três turnos fixos de trabalho. 2003. 114 f. Dissertação (Mestrado em Saúde Ambiental)-Faculdade de Saúde Pública, Universidade de São Paulo, São Paulo, 2003.
DEDECCA, C. S.; RIBEIRO, C. S. M. F.; ISHII, F. H. Gênero e jornada de trabalho: análise das relações entre mercado de trabalho e família. Trabalho, Educação e Saúde, Rio de Janeiro, v. 7, n. 1, p. 65-90, 2009. http://dx.doi.org/10.1590/S198177462009000100004 .

DORNELLES, K. N.; LEHFELD, N. A. S.; ENGLER, H. B. R. O processo de angústia no trabalho feminino: reflexões sobre a cidadania adoecida. In: SEMINÁRIO DE SAÚDE DO TRABALHADOR DE FRANCA, 7., 2010, Franca. Anais eletrônicos... Unesp Franca, Disponvel em: <http://www.proceedings.scielo.br/ scielo.php?script $=$ sci_arttext\&pid $=$ MSC000000011 2010000100006\&lng $=$ pt\&nrm $=a b n>$. Acesso em: 23 Jun. 2014.

FISCHER, F. M.; LIEBER, R. R. Trabalho em turnos. In: MENDES, R. (Org.). Patologia do Trabalho. São Paulo: Atheneu, 2007, p. 826-868.

FLICK, U. Introdução à pesquisa qualitativa. Porto Alegre: Artmed, 2009.

FREIRE, N. Conferência de Abertura: Seminário Gênero, família e trabalho em perspectiva ampliada. In: ARAÚJO, C.; PICANÇO, F.; SCALON, C. (Orgs.). Novas conciliações e antigas tensões? Gênero, família e trabalho em perspectiva comparada. Bauru: Edusc, 2007. p. 11-18.

GASPAR, S.; MORENO, C.; MENNA-BARRETO, L. Os plantões médicos, o sono e a ritmicidade biológica. Revista da Associação Médica Brasileira, São Paulo, v. 44, n. 3, p. 239-245, 1998. http://dx.doi.org/10.1590/ S0104-42301998000300013. PMid:9755554

GIANNASI, F. A precarização do trabalho das mulheres e seus impactos sobre a saúde. In: OLIVEIRA, E. M.; SCAVONE, L. (Orgs.). Trabalho, saúde e gênero na era da globalização. Goiânia: Editora AB, 1997. p. 81-86.

GIBBS, G. Análise dos dados qualitativos. Porto Alegre: Artmed, 2009.

HIRATA, H.; KERGOAT, D. Novas configurações da divisão sexual do trabalho. Cadernos de Pesquisa, São Paulo, v. 37, n. 132, p. 595-609, 2007. http://dx.doi. org/10.1590/S0100-15742007000300005.

IÑIGUEZ, L. (Org.). Manual de análise do discurso em Ciências Sociais. Petrópolis: Vozes, 2005.

INSTITUTO BRASILEIRO DE GEOGRAFIA E ESTATÍSTICA - IBGE. Síntese de Indicadores 2011 Pesquisa Nacional por amostra de domicílios. Brasília, 2012.

MACAGNAN, J. Impacto do trabalho noturno no excesso de peso e na obesidade abdominal em trabalhadores de um frigorífico no sul do Brasil. 2010. 101 f. Dissertação (Mestrado em Saúde Coletiva)Programa de Pós-Graduação em Saúde Coletiva, 
Universidade do Vale do Rio dos Sinos, São Leopoldo, 2010.

MANHÃES, V. M. S. Cronotipo e privação do sono nos trabalhadores do serviço noturno hospitalar de enfermagem. 2009. 72 f. Dissertação (Mestrado em Enfermagem)-Centro Biomédico, Faculdade de Enfermagem, Universidade do Estado do Rio de Janeiro, Rio de Janeiro, 2009.

MARCONDES, W. B. et al. O peso do trabalho "leve" feminino à saúde. São Paulo em Perspectiva, São Paulo, v. 17, n. 2, p. 91-101, 2003.

MEDEIROS, S. M. et al. Possibilidades e limites da recuperaçao do sono de trabalhadores noturnos de enfermagem. Revista Gaúcha de Enfermagem, Porto Alegre, v. 30, n. 1, p. 92-98, 2009. PMid:19653561.

MINAYO, M. C. S. O desafio do

conhecimento. Pesquisa qualitativa em saúde. São Paulo: Hucitec, 2010.

MINAYO-GOMEZ, C.; MACHADO, J. M. H.; PENA, P. G. L. (Orgs.). Saúde do trabalhador na sociedade contemporânea. Rio de Janeiro: FIOCRUZ, 2011.

MOLINO, M. D. C. B. et al. Síndrome metabólica em motoristas profissionais de transporte de cargas especiais nas rodovias do Espírito Santo. UFES Revista de Odontologia, Vitória, v. 10, n. 4, p. 37-47, 2008.

MONTAGNER, P. A reestruturação produtiva e o desemprego da mulher. In: COSTA, A. A. et al. (Orgs.). Reconfiguração das relações de gênero no trabalho. São Paulo: CUT Brasil, 2004. p. 71-80.

MORENO, C. R. D. C.; LOUZADA, F. M. What happens to the body when one works at night? Cadernos de Saúde Pública, Rio de Janeiro, v. 20, n. 6, p. 1739-1745, 2004. http://dx.doi.org/10.1590/S0102311X2004000600034. PMid:15608878

OLIVEIRA, E. M. D. Gênero, saúde e trabalho: um olhar transversal. In: OLIVEIRA, E. M. D.; SCAVONE, L. (Orgs.). Trabalho, saúde e gênero na era da globalização. Goiânia: Editora AB, 1997. p. 1-14.

OLIVEIRA, E. M. D. A mulher, a sexualidade e o trabalho. São Paulo: Hucitec, 1999.

OLIVEIRA, E. M. D. O feminismo desconstruindo e reconstruindo o conhecimento. Estudos Feministas, Florianópolis, v. 16, n. 1, p. 229-245, 2008. http:// dx.doi.org/10.1590/S0104-026X2008000100021.

OLIVEIRA, E. M. D.; BARRETO, M. Engendrando gênero na compreensão das lesões por esforços repetitivos. Saúde e Sociedade, São Paulo, v. 6, n.
1, p. 77-99, 1997. http://dx.doi.org/10.1590/S010412901997000100006.

OLIVEIRA, M. M. D. Alterações psicofisiológicas dos trabalhadores de enfermagem no serviço noturno. 2005. 128 f. Dissertação (Mestrado em Enfermagem)Programa de Pós-Graduação em Enfermagem, Escola de Enfermagem Anna Nery, Universidade Federal do Rio de Janeiro, Rio de Janeiro, 2005.

RÉGIS-FILHO, G. I. Síndrome da má-adaptação ao trabalho em turnos - Uma abordagem ergonômica. Revista Produção, São Paulo, v. 11, n. 2, abr. 2002.

RIBEIRO, M. C. (Org.). Enfermagem e trabalho: fundamentos para atenção à saúde dos trabalhadores. São Paulo: Editora Martinari, 2008.

RIO GRANDE DO SUL. Tribunal de Contas. Dados relativos à educação infantil no Estado do Rio Grande do Sul 2011. Interesse Público, Belo Horizonte, v. 14, n. 76, nov./dez. 2012.

ROTENBERG, L. Trabalhando de noite e dormindo de dia: regularidade do sono e adaptação psicológica de operárias do turno noturno. 1997. 88 f. Tese (Doutorado em Psicologia)-Instituto de Psicologia, Universidade de São Paulo, São Paulo, 1997.

ROTENBERG, L. Aspectos sociais da tolerância ao trabalho em turnos e noturno, com ênfase nas questões relacionadas ao gênero. In: FISCHER, F. M.; MORENO, C. R. D. C.; ROTENBERG, L. (Orgs.). Trabalho em turnos e noturno na sociedade 24 horas. São Paulo: Atheneu, 2004. p. 53-64.

SARDENBERG, C. M. B. O gênero do trabalho no complexo metalúrgico Norte-Nordestino. In: SARDENBERG, C. M. B. (Org.). A face feminina do complexo metal-mecânico: mulheres metalúrgicas no Norte e Nordeste. Salvador: UFBA/FFCH/NEIM/ REDOR; São Paulo: CNM/CUT, 2004. p. 51-76.

SCHIRMER, J. Trabalho e maternidade: qual o custo para as mulheres? In: OLIVEIRA, E. M. D.; SCAVONE, L. (Org.). Trabalho, saúde e gênero na era da globalização. Goiânia: Editora AB, 1997. p. 101-113.

SCOTT, J. W. Gênero: uma categoria útil de análise histórica. Educação \& Realidade, Porto Alegre, v. 20, n. 2, p. 71-99, jul./dez. 1995.

SILVA, C. A. R.; MARTINO, M. M. F. Aspectos do ciclo vigília-sono e estados emocionais em enfermeiros dos diferentes turnos de trabalho. Revista de Ciências Médicas, Campinas, v. 18, n. 1, p. 21-33, 2009. 